\title{
Mutações no campo da educação de adultos. Sobre os caminhos da formação dos educadores*
}

\section{Shifts in the field of the adult education. On training paths for adult educators}

\author{
Rui Vieira de Castro \\ Paula Guimarães \\ Amélia Vitória Sancho**
}

\begin{abstract}
RESUMO
O campo da educação enfrenta na actualidade importantes desafios que têm levado ao surgimento de tensões e dilemas que forçam a sua reconfiguração. Neste âmbito, a formação de educadores de adultos também se confronta com diversos problemas, com destaque para aqueles induzidos pela prevalência de determinados modos de conceber e entender a formação.

Foi na procura de modos alternativos e inovadores de conceber e desenvolver a formação de educadores de adultos que a Unidade de Educação de Adultos da Universidade do Minho participou no projecto $A$ Good Adult Educator in Europe (AGADE). Neste texto, procura-se dar conta da definição de seis princípios orientadores da concepção de um dispositivo de formação de educadores de adultos.

Palavras-chave: educação de adultos; dispositivos de formação de educadores de adultos.
\end{abstract}

* Este texto constitui uma versão abreviada de uma conferência apresentada no III Seminário Internacional. Educação intercultural, movimentos sociais e sustentabilidade, que ocorreu na Universidade Federal de Santa Catarina, em Florianópolis (Brasil), de 13 a 15 de novembro de 2006 .

** Rui Vieira de Castro: rvcastro@iep.uminho.pt; Paula Guimarães: pco@uea.uminho.pt; Amélia Vitória Sancho: avitoria@uea.uminho.pt. Universidade do Minho/Unidade de Educação de Adultos, Portugal. 


\begin{abstract}
In contemporary times the adult education field faces relevant shifts leading to the emergence of tensions and dilemmas that force its reconfiguration. Therefore, several problems rise in what adult educators' training is concerned, mainly these induced by the prevalence of certain forms of training.

Searching for innovative ways of conceiving and developing adult educators training, the Unit for Adult Education of the University of Minho joined the project $A$ Good Adult Educator in Europe (AGADE). In this paper, the authors wish to present six principles by which a disposal of adult educators training can be based on.
\end{abstract}

Key-words: adult education; training disposals for adult educators.

\title{
1. Lugares de partida
}

1.1. Nos países centrais e nos países da semiperiferia, o campo da educação de adultos ${ }^{1}$, nos tempos mais recentes, tem conhecido mutações radicais associadas a múltiplas causas, entre elas a crise do projecto original da educação de adultos (FINGER e ASÚN, 2001; CANÁRIO, 2006), as reconfigurações do Estado, da sociedade civil e das suas relações (DALE, 2005; LIMA e AFONSO, 2006) e os novos desafios sociais, ecológicos, políticos e culturais com os quais este campo de práticas se confronta (STROMQUIST, 1998; WELTON, 2005).

Dentre estas mutações, são particularmente significativas as que estão associadas às alterações da economia nas sociedades capitalistas e aos seus impactos nos contextos de trabalho; no quadro destas mudanças, em particular aquelas que envolvem a economia, o trabalho e a formação, tem sido atribuída uma crescente importância à educação de adultos, nomeadamente à educação, formação e aprendizagem ao longo da vida, orientação que tem arrastado consigo uma reconfiguração do trabalho dos educadores de adultos.

1 Por educação de adultos designamos o campo de práticas multifacetado que inclui áreas de intervenção, neste texto designadas de dimensões, tão variadas quanto a alfabetização, a formação, inicial e contínua, o aperfeiçoamento, a reciclagem, a animação, sociocultural e comunitária, o desenvolvimento comunitário, a intervenção socioeducativa e a educação política, entre outras (cf. LIMA et al., 1988). 
Um efeito destas mudanças, particularmente visível na União Europeia, é a sobrevalorização da "formação" relativamente a muitas outras dimensões da educação de adultos. Esta supremacia tem sustentado a necessidade do aumento de competências nos indivíduos em "idade activa", considerados "recursos humanos", com o propósito de encontrar a soluçãoformação para a crise do emprego. Assim, de direito reivindicado, a formação passou a dever (RODRIGUES e NÓVOA, 2005, p. 12), resultante da urgência de adaptar os indivíduos às transformações tecnológicas, convertendo-se assim num poderoso dispositivo de regulação social e num destino "que se é compelido a suportar para dissimular o percurso que conduz à exclusão profissional e social" (CORREIA et al., 1999, p. 5).

Estas circunstâncias têm suscitado novas reflexões sobre a formação de educadores de adultos (para o caso português, cf. ROTHES, 2003), que consideram que os novos problemas e oportunidades que os referidos profissionais enfrentam nos seus quotidianos devem suscitar novos enquadramentos, objectivos e metodologias.

Neste quadro, duas visões da formação podem ser confrontadas. $\mathrm{Na}$ linha das reflexões desenvolvidas por José Alberto Correia relativas à formação, de um lado, surgem propostas assentes na qualificação profissional, tendo por base a adequação das capacidades dos indivíduos a um conjunto de regras e funções previamente estabelecidas, a um posto de trabalho, etc., propostas estruturadas por uma racionalidade de tipo instrumental. De outro lado, encontram-se modelos alternativos de formação que incidem sobre as relações entre esta e novos modos de conceber e desenvolver o trabalho, pelos quais se apela à estruturação de práticas que poderão interferir na organização dos contextos organizacionais, muitos destes marcados pela indeterminação e pela flexibilidade, e que, por isso, tendem a centrar-se nos indivíduos e nas suas capacidades de apropriação e reapropriação (CORREIA, 1992, p. 4-9).

Enquadrada nesta última visão, a formação de educadores de adultos pode emergir como modo de reforçar as relações entre práticas formativas e práticas investigativas, com o objectivo de induzir transformações sociais - cabem aqui muitos projectos de investigação-acção-formação -; e/ou como modo de estabelecer relações mais estreitas entre educação formal e educação informal, nas quais o informal desempenha um papel estruturante, sendo "em torno dele que se tende a definir o sentido e a pertinência da 
formação intencional"2, cabendo neste caso destacar as transformações que ocorrem a nível individual (CORREIA, 1992, p. 7). De resto, esta orientação encontra expressão na importância cada vez mais evidente nos métodos autobiográficos e das histórias de vida associados à formação, em geral, e à formação de educadores de adultos, em particular.

A Unidade de Educação de Adultos da Universidade do Minho, desde a sua criação em 1976 até os nossos dias, tem levado a cabo diferentes iniciativas de formação de educadores de adultos. Estas acções variaram segundo os objectivos que perseguiram, os métodos pedagógicos que privilegiaram, e os grupos aos quais se dirigiram, centrando-se: i) na transmissão, discussão e aplicação de certos conteúdos e métodos pedagógicos, como aconteceu em muitas acções de formação de formadores; ii) na implementação de processos educativos e de intervenção social, como no caso das acções que incidiam sobre a concepção, desenvolvimento e avaliação de projectos educativos e formativos; iii) na intervenção social e educativa de organizações diversas e na formação dos seus quadros, entre estes líderes associativos, agentes de desenvolvimento local, animadores e mediadores, etc.; e iv) na reflexão sobre processos de investigação-formação-acção, como no caso dos Projecto Viana e Projecto Aprendendo no Local de Trabalho, na dinamização de círculos de estudo e de grupos de discussão em organizações hospitalares (cf. CASTRO, SANCHO e GUIMARÃES, 2006, p. 38).

Se a diversidade marcou as finalidades, os conteúdos e os modos de intervenção educativa de muitas das iniciativas atrás referidas, elas surgem unificadas pela opção, aliás teoricamente sustentável e sustentada, pela formação presencial. É na procura de novas abordagens à formação de educadores de adultos, no âmbito de mudanças sociais e educativas que têm originado outras reconfigurações do campo e da necessidade de criação de espaços alternativos, que se pode encontrar a razão principal para a participação da UEA no projecto $A$ Good Adult Educator in Europe (AGADE).

1.2. A União Europeia, no Conselho de Lisboa de 2000, assumiu como objectivo político central tornar-se a "economia baseada no conhecimento mais dinâmica e competitiva do mundo, capaz de garantir um crescimento económico sustentável, com mais e melhores empregos, e com maior co-

2 De realçar neste domínio a importância cada vez mais evidente que a abordagem preconizada pelas histórias de vida e pelo método autobiográfico assume no contexto da educação de adultos e da formação de educadores e que tem como resultado a criação de intervenções educativas e formativas centradas na reflexividade crítica (veja-se, a título de exemplo, os trabalhos de CHENÉ et al., 1988 e de CORREIA, 1998). 
esão social". A consecução deste objectivo tem vindo a envolver uma atenção particular à agenda educativa no centro da qual passou a ser colocada a educação, formação e aprendizagem ao longo da vida. Em conseqüência, a educação de adultos, ou melhor, uma sua versão, tem vindo a ganhar grande proeminência no discurso político e nas práticas de educação e formação em diferentes contextos nacionais e também em Portugal (EUROPEAN COMMISSION, 2004 e 2005).

O Programa SOCRATES, programa de acção na esfera da educação, é um dos instrumentos que a União tem adoptado para sustentar as orientações que preconiza. Este Programa organiza-se em diversas acções, entre elas a "Acção Grundtvig - Educação de Adultos e outros Percursos Formativos" que visa "melhorar a qualidade e incentivar a dimensão europeia na educação de adultos em sentido lato, contribuindo para proporcionar mais oportunidades de aprendizagem ao longo da vida". Ao abrigo desta acção, vários projectos vêm sendo desenvolvidos, entre eles o Projecto AGADE.

A partir desta experiência procuraremos, neste texto, estabelecer algumas das coordenadas que possam balizar as práticas que se desenvolvem no campo da educação de adultos, escrutinando as contradições e as tensões que a atravessam, equacionando prioritariamente alguns sentidos e possibilidades das práticas de formação dos educadores de adultos.

Foi no âmbito do Programa SOCRATES-Grundtvig que, em 2003, um conjunto de agências europeias ligadas à educação de adultos candidatou o Projecto $\mathrm{AGADE}^{3}$. Estas agências apresentavam, como ponto de partida, não só um capital de experiências amplamente diversificado, como inscreviam a sua acção em contextos em que a educação de adultos apresentava configurações muito distintas.

Este Projecto, tendo como finalidade última melhorar a qualidade e o acesso de educadores de adultos de países europeus a cursos de educadores de adultos, estruturava-se em torno de um conjunto de objectivos, de

3 Entre estas agências encontravam-se a Associação de Educação Não Formal da Estónia (Esti Vabaharidusliit - www.vilmsi.ee/ evhl), a Associação de Educação de Adultos da Lituânia (Lietvus Suaugusiuju Svietimo Asociacja - www.lssa.smm.lt), a Associação de Educação de Adultos da Letónia (Latvijas Pieauguso Izglitibas Apvieniba - www.laea.from.lv), a Associação de Educação de Adultos da Noruega (Voksenopplaeringsforbundet - www.vofo.no), a Associação para a Promoção do Estudo da Suécia (www.sfr/nas) e a Associação de Escolas Superiores Populares da Hungria (Magyar Népfiskolai Társaság - www.nepfoiskola.hu); participavam também no grupo promotor duas agências universitárias - a Universidade Nacional da Irlanda - (www.nuigalway.ie) e a Unidade de Educação de Adultos da Universidade do Minho - (www.uea.uminho.pt). 
natureza e alcance diversos, em que sobressaía a intenção de desenvolver uma abordagem curricular da formação de educadores de adultos baseada na definição de critérios estruturantes do perfil de um educador de adultos. Como objectivos complementares, surgiam o desenvolvimento de metodologias de educação à distância em acções de formação de educadores de adultos, na consideração de combinatórias com a educação presencial, e o reforço da rede de educadores de adultos na Europa, através do seu envolvimento na concepção e no desenvolvimento de dispositivos de formação baseados em equipas internacionais de formadores.

$\mathrm{Na}$ sua base, o Projecto correspondia a necessidades expressas pelas organizações parceiras de discutir o significado da formação de educadores de adultos a nível europeu, bem como as políticas da União Europeia neste campo. Assim entendido, o Projecto assumia claramente uma dimensão de desenvolvimento teórico, a partir da consideração das práticas nos diferentes terrenos, da sua interrogação e da clarificação das condições de desenvolvimento de um projecto de formação de educadores de adultos num quadro internacional, e uma dimensão de aplicação, expressa na implementação, avaliação e reorganização de um dispositivo de formação de educadores de adultos.

Nesta circunstância, considerava-se que qualquer desenho curricular deveria integrar a possibilidade da sua adequação a contextos sócioeducativos, políticos, culturais e históricos específicos ${ }^{4}$. Do desenho resultante esperava-se que servisse o desenvolvimento de competências específicas entendidas como relevantes (ao nível das competências de comunicação, das competências sociais e da pedagogia específica da educação de adultos) formuladas a partir, também, das necessidades identificadas no percurso analítico, na consideração, portanto, das competências chave associadas ao conjunto de critérios definidores do perfil de formação ${ }^{5}$.

4 O Projecto tomava, como retaguarda, um conjunto de iniciativas e debates anteriores que se tinham orientado por objectivos similares, designadamente aqueles que se tinham organizado em torno do Projecto Learning for Sharing (2000-2002) (http://www.eaea.org; http://www.learning4sharing.nu).

5 O trabalho desenvolvido no âmbito do Projecto correu em dois níveis que se pretendeu se alimentassem mutuamente. Por um lado, no plano nacional, através da constituição de um Grupo de Trabalho Nacional, e, por outro lado, no plano internacional, através de interacções com os outros parceiros; nos dois planos foram, a propósito, produzidos e discutidos diversos documentos relacionados com os perfis dos educadores de adultos, as suas competências desejáveis, os objectivos e formas de organização de desenvolvimento de dispositivos de formação. 
As características diferenciadas da oferta de formação de educadores de adultos, a que correspondem igualmente designações diversas, não é certamente separável da natureza complexa e multifacetada do campo de práticas da educação de adultos. Propor a construção de um dispositivo de formação como aquele que se encontrava previsto no Projecto AGADE aconselhava, pois, a que se tivesse em conta esta dupla diversidade - a do campo das práticas e a do campo da formação.

Neste contexto, parecia relevante ter em consideração três vectores distintos: i) a evolução da educação de adultos e a experiência adquirida não só no nível das práticas, mas também da formação de educadores de adultos; ii) as actuais orientações políticas, no quadro nacional e da União Europeia, relativas ao desenvolvimento da educação e formação de adultos, as quais enfatizam ideias tão problemáticas como o estímulo à competitividade económica e a responsabilização dos adultos pela sua empregabilidade; e iii) a defesa de um conjunto de princípios que favoreçam o respeito pela história deste campo e o seu carácter cosmopolita, a diversidade das práticas e dos métodos pedagógicos e de intervenção que o caracterizam, o envolvimento comprometido e a reflexão crítica relativamente aos quotidianos dos adultos, bem como os valores que têm orientado o desenvolvimento da educação de adultos, como a educação permanente, a democracia, a justiça, a cidadania e a igualdade.

\section{Veredas}

A partir dos lugares de partida antes sumariamente apresentados, foi adoptada uma estratégia de desenvolvimento do trabalho que supunha a realização de um conjunto de etapas que deveriam ocorrer, simultaneamente, no plano nacional e no plano internacional, envolvendo, entre outros aspectos, a definição de princípios orientadores da formação de educadores de adultos. São esses princípios que, agora, de forma necessariamente sintética, nos propomos apresentar e discutir. 
I. Primeiro princípio: um entendimento complexo da Educação de Adultos (EA)

A construção de dispositivos de formação de educadores de adultos ganha em assumir um entendimento alargado do conceito de educação de adultos, na esteira da definição que resultou da Reunião de Nairobi (UNESCO, 1977):

O conjunto de processos organizados de educação, qualquer que seja o conteúdo, o nível e o método, quer sejam formais ou não formais, quer prolonguem ou substituam a educação inicial dispensada nos estabelecimentos escolares e universitários e sob forma de aprendizagem profissional, graças aos quais pessoas consideradas como adultas pela sociedade de que fazem parte desenvolvem as suas aptidões, enriquecem os seus conhecimentos, melhoram as suas qualificações técnicas ou profissionais ou lhes dão uma nova orientação, e fazem evoluir as suas atitudes ou o seu comportamento na dupla perspectiva de um desenvolvimento integral do homem e de uma participação no desenvolvimento sócio-económico e cultural equilibrado e independente.

Nesta perspectiva, o educador de adultos deve estar em condições de participar num conjunto amplo de acções educativas configurado por variáveis como a natureza dos objectivos das acções educativas, as características dos sujeitos envolvidos naquelas acções (as formas da sua inscrição na sociedade, na economia e na própria educação), e as condições contextuais em que as acções educativas têm lugar. Em conseqüência, "É essencial que as abordagens da educação de adultos assentem no património, na cultura, nos valores e nas experiências anteriores das pessoas e que de diferentes maneiras de as pôr em prática estas abordagens facilitem e estimulem a activa participação e expressão de todo o cidadão" (UNESCO, 1998, p. 16-17).

Uma definição alargada de educação de adultos permite associar três pressupostos (cf. DELORS et al., 1996; UNESCO, 1998; CANÁRIO, 2001, entre outros):

- a continuidade e a complementaridade da educação, em termos diacrónicos, valorizando outros tempos de educação para além do escolar, uma vez que se entende que o envolvimento em processos de educação ao 
longo da vida é relevante, sendo a adultez (e não só a infância e a adolescência) um tempo de educação igualmente significativo. Para que a educação de adultos aconteça ao longo da vida, ela terá que ser considerada como um direito, acompanhado por medidas que favoreçam o seu exercício, de modo a permitir uma cidadania informada e tolerante, a autonomia, o sentido de responsabilidade, o reforço da capacidade de fazer face às transformações da economia, da cultura e da sociedade, a coexistência, a tolerância e a participação consciente e criativa, condições para que as pessoas assumam o seu destino e da sociedade e possam enfrentar os desafios que se lhes colocam;

- a diversidade da educação, seja do ponto de vista dos níveis de formalização, prevendo-se a existência de acções de carácter não formal ou informal, seja do ponto de vista das instituições promotoras de educação, escolares ou não, empresas, associações, etc., seja do ponto de vista dos contextos, profissional, social, comunitário, grupal e/ou familiar. Neste âmbito, torna-se importante a existência de uma interligação eficaz entre os sistemas formal e não formal, tendo em vista a criação de uma sociedade educativa empenhada na justiça social e no bem-estar de todos, como efeito da articulação de relações entre as tradicionais instituições de ensino e educação e as organizações directa ou indirectamente promotoras de educação, as empresas enquanto locais de trabalho, as organizações da sociedade civil, os sindicatos, os movimentos sociais, entre outros;

- a globalidade da educação, seja ao nível da pessoa que se educa (no sentido em que a educação deverá ter em consideração o sujeito na sua totalidade e a diversidade entre os indivíduos no que respeita ao género, à idade, ao grupo social e cultural de pertença, etc.), seja da inscrição das práticas educativas nos níveis local, nacional e global. Assim, num mundo marcado por transformações diversas, a educação de adultos desempenha um papel essencial e específico no sentido de proporcionar a todos os meios que permitam a sua construção multidimensional num quadro em que ganham relevo a promoção da democracia, da justiça, da cidadania, da igualdade e da participação.

II. Segundo princípio: um entendimento da EA como processo de educação ao longo da vida

A construção de um dispositivo de educadores de adultos deverá ser efectuada partindo do entendimento da educação de adultos à luz do conceito de educação permanente (cf. FAURE et al., 1972), percebida como 
processo educativo que coexiste com a própria vida dos adultos, não podendo, em conseqüência, ser exclusivamente concebida como um momento de preparação para a vida ou para uma etapa da vida. Neste contexto, a educação permanente favorece a definição da educação de adultos como percurso no qual se "aprende a ser". A educação de adultos, assim conceptualizada: i) permite criar condições para que os adultos se beneficiem de novos conhecimentos que venham a ser construídos e definidos pelo desenvolvimento científico, tecnológico, social, cultural, etc.; ii) favorece a existência de uma atitude de questionamento científico e problematização constante face ao mundo e às mudanças que ocorrem; iii) facilita a promoção de um olhar crítico sobre as crenças, convicções, ideologias, hábitos e costumes que não se podem constituir como padrões ou regras imutáveis; e iv) encoraja o desenvolvimento de novos saberes e alterações nos comportamentos e atitudes de cada pessoa (LENGRAND, 1989, p. 8). Decorre daqui uma valorização da educação como problema político, bem como a necessária consideração dos processos educativos estando centrados nos fins (e não exclusivamente nos meios), envolvendo a consideração do sujeito como agente da sua própria educação.

Nesta linha de pensamento, um dispositivo de formação de educadores de adultos deverá promover quatro aprendizagens fundamentais: aprender a conhecer, aprender a fazer, aprender a viver juntos e aprender a ser (DELORS et al., 1996, p. 77-103), evitando privilegiar uma destas dimensões. Este entendimento favorece a concepção de educação de adultos como prática que inclui a aprendizagem ao longo da vida, como a União Europeia a tem entendido (COMISSÃO EUROPEIA, 2000), mas que a ela se não resume. Embora retome a discussão iniciada pela educação permanente (cf. FAURE et al., 1972 e DELORS et al., 1996) relativa aos desafios e às mudanças com os quais se confrontam as sociedades ocidentais, o conceito de aprendizagem ao longo da vida enfatiza outros, como a aquisição e renovação de competências pelos indivíduos na sociedade do conhecimento, a avaliação dos resultados da aprendizagem, o desenvolvimento de métodos de ensino e aprendizagem eficazes para uma oferta que responda às necessidades do mercado de emprego e a importância de prover oportunidades de aprendizagem tão próximas quanto possível dos adultos-aprendentes (COMISSÃO EUROPEIA, 2000, p. 4); nesta perspectiva, valoriza-se uma lógica centrada prioritariamente na consideração dos meios e preocupada com a eficácia, a qualidade, a competitividade, a produtividade e a empregabilidade, assumindo o conceito, por isso, contornos redutores enquadrando-se numa estratégia de reforço do valor de mercado da educação. 
III. Terceiro princípio: a EA como prática promotora da democracia e cosmopoliticidade

A educação de adultos vive actualmente tempos complexos, sendo atravessada por tensões entre discursos que enfatizam a democracia e a cidadania, na linha dos princípios definidos pela educação permanente, hoje claramente minoritários, pelo menos na Europa, em termos da sua visibilidade na esfera pública, e discursos nos quais a aprendizagem ao longo $d a$ vida e a formação profissional são privilegiadas, sendo os seus desenvolvimentos apoiados por políticas definidas e desenvolvidas por instituições como a União Europeia. No actual contexto político e social de globalização e, no caso português, de inclusão na União Europeia, são hoje dominantes políticas que preconizam uma subordinação ao mercado, baseadas em abordagens que enfatizam a competição, a eficiência e a eficácia, a empregabilidade e o empowerment de consumidores (e não o empowerment de cidadãos) (LIMA, 1995, p. 39).

Para além dos valores da democracia e da cidadania, outros como os da justiça social, da liberdade e da igualdade são por nós entendidos como devendo estruturar as políticas sociais. Numa acepção de carácter mais liberal e humanista, a justiça apresenta-se intimamente ligada a políticas distributivas, centrando-se naquilo que as pessoas precisam na sua condição de cidadãos livres e iguais e de membros plenamente cooperantes da sociedade em que se integram (cf. RAWLS, 1978). A este propósito, a argumentação de Carlos Vilar Estêvão (2001, p. 11) pode constituir um importante referencial para a construção e o desenvolvimento de dispositivos de formação de educadores de adultos:

(...) os cidadãos devem ser tratados como iguais diante da intervenção pública em todos as esferas do domínio social, ainda que a própria estrutura de classe os posicione de modo desigual quanto à repartição de benefícios e distribuição de desigualdades e, portanto, quanto à questão da justiça. (...) a questão da justiça, entendida sobretudo como "uma distribuição justa de bens sociais", é essencial a qualquer sociedade para que esta sobreviva como uma comunidade política adulta e democrática.

Porém, esta justiça que garante aos cidadãos direitos de segurança social e económica, de educação e saúde, entre outros, vem sendo ameaçada 
pela crise (ou redefinição) do Estado-Providência e pelo surgimento de novas formas de discriminação e exclusão, assim como pela naturalização de formas de darwinismo social (LIMA, 1995, p. 40).

Ganha assim sentido acrescido a construção de dispositivos de formação de educadores de adultos baseados nos valores da democracia, da cidadania, da justiça, da igualdade e da solidariedade, favorecendo a sua problematização e procurando formas de reinvenção e de democratização da democracia (LIMA, 1995 e SANTOS, 1998). Este entendimento de democracia enfatiza o desenvolvimento pluralista e interdependente das sociedades individualmente consideradas e da sociedade globalmente perspectivada, o respeito pela diversidade de culturas, sentidos e objectivos, a responsabilidade social, a participação nos seus diferentes aspectos, na promoção de uma política emancipatória, que compreende uma visão cosmopolítica da realidade social e da educação em particular (ARCHIBUGI, 2000) e favorece a cosmopoliticidade (cf. ESTÊVÃO, 2004).

IV. Quarto princípio: a EA como prática receptiva às dimensões educacionais das práticas sociais

Qualquer projecto de educação possui sempre uma dimensão política que deve ser escrutinada. Toda a acção educativa se constitui numa arena onde se jogam diferentes percepções, interesses, motivações e convicções que podem favorecer a potenciação de formas emancipatórias ou a alienação e a submissão. Neste contexto, as acções educativas não podem ser tidas como processos neutros, uma vez que não estão separadas das condições históricas de produção e dos interesses ideológicos que as sustentam (FREIRE, 1975; GIROUX, 1983). Na perspectiva que aqui se adopta, a educação deve permitir avaliar as estruturas de possibilidade (GIROUX, 1992, p. 61), permitindo que os adultos reflictam, actuem, transformem os seus quotidianos, através da promoção de processos participados orientados para a criação de oportunidades nas quais se registre a apropriação da realidade e a sua transformação. A consciência crítica das realidades, associada à compreensão das dimensões políticas das diferentes formas de conhecimento, é, neste quadro, entendida como objectivo fundamental. Para que o trabalho de educadores e educandos possa constituir-se como um trabalho não alienado, é então imperativo contrariar a subordinação funcional da educação à racionalidade económica, apostando numa educação comprometida com o humano, com o social, com o ambiental, que se afaste de lógicas meramente reprodutivas e alienantes. Nesta medida, é 
importante que a educação de adultos permita reflectir criticamente as práticas educativas inscritas nos processos sociais, sendo conseqüentemente relevante incorporar nos dispositivos de formação estratégias assentes em modos de intervir baseados na pedagogia crítica, emancipadora e problematizadora (FREIRE, 1975), que permitam compreender como os adultos integram e perspectivam nas suas vidas e nos modos de acção individual e colectiva práticas de educação formal, não formal e informal.

V. Quinto princípio: a EA como campo de práticas, formas e níveis diversos

Constituindo-se a educação de adultos num campo de práticas heterogéneo, inclui um conjunto razoavelmente diversificado de modalidades e áreas de intervenção. Embora, como afirmam diversos autores (LIMA, 1992; FINGER e ASÚN, 2001; entre outros), se possa verificar um desfasamento entre o pensamento teórico e a produção científica, por um lado, e as práticas, o desenvolvimento de projectos e a acção educativa, por outro, na sua prática profissional, os educadores de adultos devem ter em conta a diversidade do seu campo e o menor ou maior grau de desenvolvimento que certas modalidades de educação de adultos podem apresentar. Estes pressupostos sugerem também a existência de distintos métodos educativos, contemplando não só aqueles que se baseiam na transmissão de conhecimentos ou na reprodução de comportamentos, mas também aqueles que se centram sobre o questionamento dos saberes, e de distintos grupos de participantes, aqueles que procuram novos conhecimentos e certificações por razões económicas e profissionais, e/ou os que através da educação desejam intervir do ponto de vista social, político, cívico, cultural, etc., melhorar a sua situação económica e profissional ou ocupar os seus tempos de lazer.

Esta diversidade deve ser perspectivada num dispositivo de formação de educadores de adultos, uma vez que as práticas educativas que podemos encontrar tendem em muitos casos para a formalização e para a reprodução do modelo escolar. De resto, como refere Rui Canário, a escola instituiu um modo de socialização que se tornou hegemónico, originando um processo de naturalização que se tornou evidente devido à extensão da oferta escolar, em particular após a II Guerra Mundial, o qual arrastou a contaminação das modalidades educativas não-escolares e, mais especificamente, daquelas modalidades educativas dirigidas a públicos adultos. Estes efeitos resultaram assim num empobrecimento da diversidade das modalidades educativas que perspectivam a experiência dos aprendentes como 
algo que não se torne um obstáculo ao conhecimento (CANÁRIO, 2001, p. 86-87). Neste sentido, haverá uma necessidade de desescolarizar a educação de adultos e de revalorizar epistemologicamente a experiência dos aprendentes, promovendo modalidades de educação não-formal e reflectindo criticamente sobre os saberes da experiência.

Conseqüentemente, estes aspectos devem ser tidos em consideração na construção de um dispositivo de formação de educadores de adultos, de forma a incluir estas diferentes facetas.

A educação de adultos comporta modalidades, momentos e espaços variados de educação e envolve sujeitos que se inscrevem (ou são inscritos) diferenciadamente nos seus contextos de vida. Considerar a diversidade de práticas e de modalidades de intervenção não pode fazer esquecer a diversidade dos níveis de acção nos quais as práticas de educação de adultos actualmente acontecem - local, regional, nacional e internacional. Neste contexto, a acção não deve ser exclusivamente concebida de "cima para baixo", mas também e sobretudo de "baixo para cima", fomentando o cruzamento das lógicas do local e do global. Ganha evidência, então, a importância de construir modos de intervenção entendidos enquanto espaços públicos de acção, caracterizados pela dialogicidade (FREIRE, 1975) e pelo diálogo polifónico.

VI. Sexto princípio: a EA como lugar de articulação da teoria e da prática

Um dispositivo de formação de educadores de adultos deverá assentar numa abordagem transdisciplinar, baseada na escolha de um tema e das diversas disciplinas que o caracterizam, que integre diversos conhecimentos e saberes em torno de uma situação real, simulada ou de um problema, que procure simultaneamente garantir uma transferência entre os conhecimentos e as estratégias cognitivas. Neste âmbito, entende-se que o desenvolvimento do currículo é um processo de representação, formação e transformação da vida social na sociedade; a prática do currículo e a experiência dos educandos deve entender-se como um todo, de forma sintética e compreensiva, que ultrapassa as perspectivas mais redutoras das especialidades e das disciplinas particulares. Por outro lado, é relevante um currículo que permita realizar uma articulação entre a teoria e a prática, que simultaneamente contemple as funções da teoria como fonte de regulação da prática e a prática também como fonte para as teorias. Este modo de abordar os problemas da teoria e da prática proporciona caminhos para entender a sua relação como sendo social e historicamente construída e praticada 
(KEMMIS, 1988, p. 44). Esta opção favorece a aproximação entre a experiência e o significado que é atribuído a esta última e através da reflexão o conhecimento implícito ganha contornos então desconhecidos para o próprio indivíduo, podendo fomentar a acção e a mudança social (MEZIROW, 1991).

\section{Pedras no meio do caminho}

Como foi referido no ponto 1 . deste texto, é evidentemente problemática a possibilidade de se desenhar um currículo para um dispositivo de formação de educadores de adultos que não incorpore $a b$ initio as características das áreas de intervenção educativa e formativa, os públicos com quem se espera que os educadores trabalhem, os objectivos associados às acções educativas em que poderão estar envolvidos e o perfil de educador de adultos que se pretende formar. Não deixa de ser verdade também o facto de cada vez mais educadores de adultos serem confrontados com solicitações de intervenção no quadro de acções de natureza diferenciada, com objectivos educacionais e públicos distintos.

Estas ordens de razões, que justificam a tarefa empreendida neste texto, de ensaiar os fundamentos da definição de um perfil de educador de adultos, foram aqui incorporadas, procurando-se delimitar um conjunto de princípios gerais, reconduzíveis a quadros de referência que são explicitados, que dê corpo a um olhar sobre a educação de adultos, que projecte $u m$ horizonte de finalidades, um caminho metodológico para o procurar, um entendimento dos sujeitos envolvidos no processo educativo.

As possibilidades de concretização deste dispositivo confrontam-se com as características das coordenadas em que se desenvolve a acção de muitos educadores de adultos num campo marcado por tensões e contradições muito profundas, potenciadas pela natureza da regulação que sobre o campo é exercida pelas instâncias nacionais e da União Europeia, e que emergem com particular visibilidade quando, por exemplo, se pretende promover perfis de formadores de educadores de adultos e modalidades de formação marcadas por um "registo de tecnicidade" (CORREIA, 1998, p. 144). Estas circunstâncias tornam-se ainda mais problemáticas se for considerado que a educação de adultos se move num tempo no qual diversos 
agentes, públicos, privados ou do terceiro sector, proclamam a urgência de um mercado da educação, no qual a escolha livre suporte a definição de percursos educativos e formativos mais consentâneos com as necessidades da economia (LIMA, 1995 e LIMA e AFONSO, 2006).

Afrontando dinâmicas poderosas, resultantes da globalização, do desenvolvimento menos controlado do capitalismo, da erosão e do descrédito da política, da redefinição do papel do Estado e da sua intervenção na educação, bem como da degradação ecológica, a educação de adultos deverá, a nosso ver, manter a sua aposta na criação de modos de intervenção que levem à existência de comunidades e sociedades sustentáveis, estruturando a sua acção na combinação de três eixos: i) integrando formas educativas que favoreçam a conscientização (FREIRE, 1975); ii) reinventando modos de intervenção social e educativa que afrontem a alienação; e iii) implicando os educadores de adultos na acção e na investigação social e educativa, em práticas que se estendam para além dos espaços educativos mais tradicionais (como, por exemplo, a sala de aula). É num contexto histórico específico que se deverá repensar o papel dos educadores de adultos e procurar conceber (con)figurações formativas alternativas que enquadrem a sua intervenção, tendo em consideração a necessidade de reflectir e recriar as articulações políticas entre a aprendizagem, o poder e a mudança nas organizações e nas sociedades às quais estes profissionais pertencem.

\section{REFERÊNCIAS}

ARCHIBUGI, D. Cosmopolitical democracy. New Left Review, vol. 40, n. 4, p. 137-150, 2000.

CANÁRIO, R. Adultos - da escolarização à educação. Revista Portuguesa de Pedagogia, n. 35, v. 1, p. 85-99, 2001.

CANÁRIO, R. Tensões e desafios da educação de adultos na actualidade. Intervenção proferida por ocasião do seminário comemorativo dos 30 anos da Unidade de Educação de Adultos da Universidade do Minho. Braga (Portugal), 2006.

CASTRO, R. V.; SANCHO, A. V.; GUIMARÃES, P. A. Unidade de Educação de Adultos. Percursos e testemunhos. Braga: Universidade do Minho-Unidade de Educação de Adultos, 2006. 
CHENÉ, A. et al. O método (auto)biográfico e a formação: antologia. Lisboa: Ministério da Saúde, 1988.

CORREIA, J. A. Dispositivos e disposições na formação de adultos: a dinâmica da formatividade. Comunicação apresentada no II Congresso da Sociedade Portuguesa de Ciências da Educação. Braga (Portugal), 1992.

CORREIA, J. A. Para uma teoria crítica em educação: contributos para uma recientifização do campo educativo. Porto: Porto Editora, 1998.

CORREIA, J. A. (Org.); LOPES, A.; MATOS, M.; FELGUEIRAS, M. Formação de professores. Da racionalidade instrumental à acção comunicacional. Porto: Edições Asa, 1999.

DALE, R. A globalização e a reavaliação da Governação Educacional. Um caso de ectopia sociológica. In: TEODORO, A.; TORRES, C. A. (Orgs.). Educação crítica e utopia. Perspectivas para o Século XXI. Porto: Edições Afrontamento, p. 53-70, 2005.

DELORS, J. et al. Educação: um tesouro a descobrir. Rio Tinto: Edições Asa, 1996.

ESTÊVÃO, C. V. Justiça e educação. São Paulo: Cortez, 2001.

ESTÊVÃO, C. V. Educação, justiça e democracia: um estudo sobre as geografias da justiça em educação. São Paulo: Cortez Editora, 2004.

EUROPEAN COMMISSION. A memorandum on lifelong learning. Brussels: Official Publication Department of the European Communities, 2000.

EUROPEAN COMMISSION. The Copenhagen Declaration. Brussels: Official Publication Department of the European Communities, 2002. Disponível em: < http:// europa.eu.int/comm/education/copenhagen/copenhagen-declaration-en.pdf. $>$ Acesso em 13 abril 2005.

EUROPEAN COMMISSION. Education \& Training 2010. The success of the Lisbon Strategy hinges on urgent reforms. Brussels: Official Publication Department of the European Communities, 2004.

EUROPEAN COMMISSION. Working together for growth and jobs. A new start for the Lisbon Strategy. Brussels: Official Publication Department of the European Communities, 2005.

FAURE, E. et al. Learning to be. The world of education today and tomorrow. Paris: UNESCO, 1972.

FINGER, M.; ASÚN, J. M. Adult education at the crossroads: learning our way out. Londres: Zed Books, 2001.

FREIRE, P. Pedagogia do oprimido. Porto: Edições Afrontamento, 1975.

GIROUX, H. A. Pedagogia radical. Subsídios. São Paulo: Cortez Editora, 1983. 
GIROUX, H. A. Alfabetización, poder y democracia. In: FLECHA, R.; GIROUX, H. A. Igualdad educativa y diferencia cultural. Barcelona: El Roure, p. 9-26, 1992.

KEMMIS, S. El currículo: más allá de la teoría de la reproducción. Madrid: Morata, 1988.

LENGRAND, P. Lifelong education: growth of the concept. In: TITMUS, C. J. (Edt.) Lifelong education for adults. An international handbook. Oxford: Pergamon Press, p. 59, 1989.

LIMA, L. C. Portugal. In: JARVIS, P. (Edt.). Perspectives on adult education and training in Europe. Leicester: NIACE, p. 178-189, 1992.

LIMA, L. C. The democratisation of democracy. A south European view on European democracy and citizenship education. In: TIMMER, J.; VELDHUIS, R. (Edts.). Political education towards a European democracy. Amsterdam: Institut voor Publiek en Politiek, p. 38-44, 1995.

LIMA, L. C.; (Coord.); ESTÊVÃO, M. L.; MATOS, L.; MELO, ALBERTO; MENDONÇA, M. A. Documentos preparatórios III. Reorganização do subsistema de educação de adultos. Lisboa: Ministério da Educação/Comissão de Reforma do Sistema Educativo, 1988.

LIMA, L. C.; AFONSO, A. J. Políticas públicas, novos contextos e actores em educação de adultos. In: LIMA, L. C. (Org.). Educação não escolar de adultos. Iniciativas de educação e formação em contexto associativo. Braga: Universidade do Minho-Unidade de Educação de Adultos, 2006.

MEZIROW, J. Transformative dimensions of adult learning. San Francisco: JosseyBass Publishers, 1991.

RAWLS, J. Teoria de la justicia. Madrid: Fundo de Cultura Económica, 1978.

RODRIGUES, C.; NÓVOA, A. Prefácio. In: CANÁRIO, R.; CABRITA, B. (Org.). Educação e formação de adultos. Mutações e convergências. Lisboa: EDUCA, p. 7-14, 2005.

ROTHES, L. A. A formação de educadores de adultos em Portugal: trajectos e tendências. Forum, n. 34, p. 35-62, 2003.

SANTOS, B. de S. Reinventar a democracia. Lisboa: Gradiva, 1998

STROMQUIST, N. P. NGOs in a new paradigm of civil society. Current issues in comparative education, v. 1, n. 1, p. 62-67, 1998.

UNESCO. Recomendações sobre o desenvolvimento da educação de adultos. Braga: Universidade do Minho, 1977.

UNESCO. V Conferência Internacional sobre Educação de Adultos. Hamburgo 1997. Declaração Final e Agenda para o Futuro. Lisboa: Ministério da Educação, 1998. 
CASTRO, R. V.; GUIMARÃES P.; SANCHO A. V. Mutações no campo da educação de...

WELTON, M. Civil society. In: ENGLISH, L. M. (Edt.). International encyclopedia of adult education. Nova Iorque: Palgrave MacMillan, p. 100-106, 2005.

Texto recebido em 10 de out. 2006

Texto aprovado em 30 de jan. 2007 